\title{
Regulation of hsc70 Expression in the Human Histiocytic Lymphoma Cell Line, U937
}

\author{
Tohru Marunouchi ${ }^{\dagger}$ and Hiromi Hosoya \\ Division of Cell Biology, Institute for Comprehensive Medical Science, Fujita Health University, Toyoake, \\ Aichi 470-11, Japan
}

Key words: hsc70/transcription/translation/U937

\begin{abstract}
$A B S T R A C T$. The transcription of hsc70, a cognate member of the hsp70 gene family, is suppressed in the terminally differentiated human histiocytic lymphoma cell line, U937, and appears to be regulated in the absence of heat shock. We have examined the $5^{\prime}$ upstream regulatory region of 450 bp which contains a putative regulatory sequence of $18 \mathrm{bp}$ in addition to known cis-elements such as HSEs, CCAAT boxes, Sp1 binding sites and AP2 binding sites. The 18 bp cis-element formed larger complexes with nuclear localized transfactors when extracts were prepared from differentiated rather than from proliferating cells. These larger complexes were also detected in nuclear extracts of serum-deprived cells, suggesting that such complexes may be related to the suppression of hsc70 gene transcription in Go arrested cells.

The level of HSC70 protein as determined using monoclonal antibodies, increased threefold in differentiated cells. The apparent discrepancy between the levels of hsc70 mRNA and HSC70 protein can be explained by a rapid turnover of $\mathrm{HSC70}$ in proliferating cells.
\end{abstract}

The hsc70 gene is a member of the major heat shock protein (hsp70) family. Most genes of this family are expressed under appropriate conditions or within a limited range of cell types (26); however, hsc70 is expressed constitutively in various tissues (11). cDNA clones and genomic clones of hsc70 isolated from the mouse and human have been sequenced $(28,37,9)$. Recently, a gene homologous to hsc70 has also been found in Drosophila (31).

Unlike other members of the hsp 70 family, hsc70 contains several introns. The structures of mammalian hsc70 genes of different species are very similar to each other. Furthermore, U14 snRNA genes have been found in introns 5, 6, and 8 of mammalian hsc70 (24, $23)$. Since these genes do not contain their own promoters, their expression is thought to be dependent on transcription of the hsc70 gene.

Regulation of gene expression of proteins of the heatinducible hsp70 family has been extensively studied (2, 26). It is known to be influenced by heat shock, metal ion, serum, viral infection (19), cell cycle (25), cell proliferation, and oncogenes (20). Expression of most of these proteins is regulated through a complex consisting of a heat shock element and a heat shock factor (HSEHSF) $(36,22)$. Expression of human hsc 70 has been described $(13,14)$ as well as that of its counterpart in the

\footnotetext{
${ }^{\dagger}$ To whom correspondence should be addressed.
}

mouse gene (6). hsc70 mRNA transcription is not signifcantly induced by heat shock and is more abundant in growing (37) or transformed cells than in resting or nontransformed cells (32). In human lymphocytes, its transcription is stimulated by mitogens (14) and its synthesis is more extensive in early mouse embryo cells than in matured tissue cells (11). The regulation of hsc70 expression, however, has not been fully elucidated in spite of the physiological importance of this protein, presumably because of its low responsiveness to stress and its strong structural similarity to hsp70.

The precise function of the HSC70 protein has not been fully elucidated but it is thought to function as a molecular chaperone in normal cells $(29,30)$ in such processes as the folding and assembly of nascent polypeptide chains $(3,10)$, clathrin uncoating of coated vesicles (38) protein transport across the membrane $(7,4$, 34 ), and targetting heat-shocked nucleoli (39).

We examined changes in the amounts of hsc70 mRNA and HSC70 protein during the course of differentiation of the human histocytic lymphoma cell line, U937, using a cDNA fragment of hsc70 and a monoclonal antibody for HSC70 protein (15). By treatment of U937 cells with 12-o-tetradecanoylphorbol-13-acetate (TPA), the mRNA level decreased to about 30\%, whereas the HSC70 content increased by about threefold within the same period. A decrease in the amount of hsc70 mRNA was also observed in serum-deprived 
culture. A candidate for the DNA sequence related to suppression of transcription was found in the $5^{\prime}$ upstream regulatory region. The mechanism of the transcriptional and post-transcriptional regulations of hsc70 is discussed.

\section{MATERIALS AND METHODS}

Cell culture. The human histiocytic lymphoma cell line, U937, was used throughout the experiments. Cells were cultured in RPMI1640 medium supplemented with 10\% fetal calf serum (Gibco, NY, USA), $0.1 \mathrm{mg} / \mathrm{ml}$ streptomycin (Wako, Osaka, Japan) and 100 units $/ \mathrm{ml}$ penicillin (Meiji, Tokyo, Japan) at $37^{\circ} \mathrm{C}$ in a humidified atmosphere of $95 \%$ air and $5 \% \mathrm{CO}_{2}$. For differentiation into macrophages, cells were treated with $0.1 \mu \mathrm{g} / \mathrm{ml} \mathrm{TPA}$ for two days and for differentiation into monocytes, $1 \mu \mathrm{M}$ retinoic acid (RA) was used for three days $(27,17)$.

For transformation, $2 \times 10^{6}$ cells were mixed with $2 \mu \mathrm{g}$ plasmid DNA in $40 \mu \mathrm{l}$ of calcium- and magnesium-free phosphate-buffered saline (PBS) and transfected using a somatic hybridizer SSH-1 (Shimadzu, Kyoto, Japan).

CAT assay. Transfected cells were cultured for $48 \mathrm{~h}$, harvested, washed with $\mathrm{PBS}$, and suspended in $0.25 \mathrm{M}$ Tris- $\mathrm{HCl}$ ( $\mathrm{pH}$ 7.8). Cellular extracts were then prepared by three cycles of freezing and thawing, sonication and centrifugation at $1,200 \times \mathrm{g}$ for $5 \mathrm{~min}$. Chloramphenicol acetyl transferase (CAT) activity was measured by the method of Gorman et al. (12), using ${ }^{14} \mathrm{C}$-labeled chloramphenicol. Chromatograms were examined with a Fuji image analyzer BA100 (Fuji Film, Tokyo, Japan).

Gel-shift analysis. Nuclear extracts (NE) prepared from proliferating, differentiated, or serum-starved cells by the method of Dignam et al. (8) were incubated at $25^{\circ} \mathrm{C}$ for 30 min with DNA fragments end-labeled with $\left[\gamma-{ }^{32} \mathrm{P}\right] \mathrm{ATP}$. The standard reaction mixture $(20 \mu \mathrm{l})$ contained $1 \mathrm{ng}$ DNA fragments, $3 \mu \mathrm{g} \mathrm{NE}$ protein, $1 \mathrm{mM} \mathrm{MgCl}_{2}, 12.5 \mathrm{mM}$ spermidine (Sigma), $0.15 \mathrm{mg} / \mathrm{ml}$ poly(dI-dC) (dI-dC) (Pharmacia), 10 $\mathrm{mM} \mathrm{KCl}, 0.1 \mathrm{mM}$ EDTA, $0.25 \mathrm{mM}$ DTT, and $10 \mathrm{mM}$ HEPES (pH 7.9). Reaction mixtures were then applied to a $4 \%$ polyacrylamide gel in $0.25 \times$ TBE buffer (TBE: $89 \mathrm{mM}$ Tris, $89 \mathrm{mM}$ boric acid, $25 \mathrm{mM}$ EDTA, pH 8.3). Gel plates were examined with a Fuji image analyzer BA100.

Genes and plasmids. We isolated the cDNA of hsc70 from a U937 cell cDNA library as a clone actively expressed in the proliferating phase. It is composed of $2,227 \mathrm{bp}$ and its sequence is almost the same as that reported previously (9) except for three base substitutions that did not affect the encoded amino acid. The genomic DNA of hsc70 was cloned from a human genomic library, supplied by the Japanese Cancer Research Resources Bank (JCRB), using the $0.56 \mathrm{kbp}$ EcoRI fragment of the $3^{\prime}$ terminal region of hsc70 cDNA (c0.56) as the probe. Two clones, Cl.31 and Cl.34, were obtained from about $10^{6}$ plaques and restriction maps of their overlapping areas were completely identical and in accordance with the reported sequence (9). The $0.83 \mathrm{kbp}$ EcoRI fragment of $\mathrm{Cl} .31$ which gave the strongest signal in the hybridization experiment with 0.56 was sequenced and the nucleotide sequence completely coincided with 0.56 within the overlapping region and with that reported previously. The $\mathrm{Cl} .31$ used in this study and its restriction map are shown in Fig. 2A. Genomic DNA of hsp70 (pH 2.3, 40) was kindly supplied by Dr. R. Morimoto of Northwestern University, Illinois.

For the CAT assay, DNA fragments derived from the $5^{\prime}$ upstream region of hsc70 which contained a TATA-element (PR1.4, Fr443, and Fr150) were inserted into pSV0-CAT or pSK-CAT, and those which did not contain a TATA-element (Fr130, Fr90, Fr50, and Fr120) were inserted into pCAT-A (16). pSK-CAT which was modified so as to have multicloning sites in place of the HindIII site of pSV0-CAT was supplied by Dr. M. Yamaguchi of the Aichi Cancer Center Research Institute.

Northern and dot hybridization. RNA was prepared by the method of Chomczynski and Sacchi (5). Eight $\mu \mathrm{g}$ of total RNA was separated on a $1.2 \%$ agarose gel in $1 \times$ MOPS buffer (20 mM MOPS (pH 7.0), $5 \mathrm{mM}$ sodium acetate, $1 \mathrm{mM}$ EDTA, 2\% formaldehyde), transferred to a nitrocellulose membrane (Hybond-C, Amersham, London, UK) and fixed by baking at $80^{\circ} \mathrm{C}$ for $2 \mathrm{~h}$. For the dot blot assay, RNA from $10^{6}$ proliferating or differentiating cells was used.

Radiolabeled DNA probes were prepared using the Multiprime Labeling System (Amersham, London, UK). Hybridization was performed under almost the same conditions as described (33), except that the hybridization solution contained $100 \mu \mathrm{g} / \mathrm{ml}$ of sonicated single-stranded salmon sperm DNA and did not contain SDS.

Footprinting and DNA sequencing. The radiolabeled DNA fragment was trimmed with a restriction enzyme to recover the fragment labeled on one terminus from the electrophoresis gel. The resultant DNA fragment which was present in the same reaction mixture used in the gel-shift assay was incubated with DNaseI (Sigma, St. Louis, USA) at a concentration of 36 units $/ \mathrm{ml}$ at $30^{\circ} \mathrm{C}$ for $45 \mathrm{sec}$. After purification, DNA was denatured in a solution containing $95 \%$ formamide, $0.25 \%$ xylene cyanole, and $0.25 \%$ bromophenol blue at $95^{\circ} \mathrm{C}$ for $3 \mathrm{~min}$ and separated by gel electrophoresis $(6 \mathrm{M}$ urea $/ 6 \%$ polyacrylamide $/ 1 \times \mathrm{TBE}$ ).

To determine the nucleotide sequence, the DNA fragment was inserted into the multicloning site of pUC118 and transfected into E. coli MV1184. The single-stranded plasmid was harvested after infection with the helper phage, $\mathrm{KO}$ 7, and the sequence was determined by the dideoxy method using an Ampli Taq Sequencing Kit (Takara, Kyoto, Japan) and the same gel as that used in footprinting.

Western blotting. SDS-polyacrylamide gel electrophoresis (SDS-PAGE) was performed according to the method of Laemmli (21). Proteins were transferred to a PVDF membrane filter (Nihon Millipore, Tokyo, Japan) using a semi-dry blotter (Kem-En-Tech, Copenhagen, Denmark). The blotted filter was treated either with rat monoclonal antibody or rab- 
bit polyclonal antibody and with a biotinylated 2nd antibody and visualized using an Immunostaining HRP Kit (Konica, Tokyo, Japan). Results were analyzed with a digitizer (ACI Japan, Tokyo, Japan). Rat monoclonal antibody, 1B5, and rabbit polyclonal antibody, No. 4, both reactive with HSC70 (15), were kindly supplied by Dr. K. Ohtsuka of the Aichi Cancer Center Research Institute.

Immunoprecipitation. Cells pulse-labeled with $25 \mu \mathrm{Ci} / \mathrm{mI}$ $\left[{ }^{35} \mathrm{~S}\right]$ methionine (Met, ICN, $1123 \mathrm{Ci} / \mathrm{mmol}$ ) for $2 \mathrm{~h}$ were washed with PBS and lysed in a solution containing $50 \mathrm{mM}$ Tris- $\mathrm{HCl}(\mathrm{pH} 8.0), 0.15 \mathrm{M} \mathrm{NaCl}$, and $1 \%$ Triton $\mathrm{X}-100$. The cellular lysate of $10^{6}$ cells was subjected to immunoprecipitation performed as described (33), using protein $G$ sepharose (ZYMED, CA, USA) as carrier.

\section{RESULTS}

U937 cells derived from a human histiocytic lymphoma differentiate into monocytes or macrophages by treatment with retinoic acid (RA) or TPA, respectively $(27,17)$. In order to analyze the expression of hsc70 during the course of differentiation, a 3 terminal $560 \mathrm{bp}$ fragment of hsc70 cDNA and a $2.3 \mathrm{kbp}$ DNA fragment of hsp70 (40) were used as the probes for Northern hybridization (Fig. 1A). It was necessary to ascertain that the probe used in this study did not exhibit cross-reactivity with other members of the hsp 70 gene family since these are conserved during evolution and especially since hsp70 and hsc70 have homologous nucleotide sequences $(9,18)$. We used a $3^{\prime}$ terminal fragment of the hsc70 coding region since this region differs most from that of hsp70 and did not hybridize with $\mathrm{pH} 2.3$, the hsp70 probe, under normal stringent conditions as described by Hansen et al. (14). Proliferating U937 cells expressed hsc70 abundantly and hsp70 slightly (Fig. 1B, lanes 1, 3). When cells were treated with $\mathrm{Zn}^{+}$as the stress inducer, hsp 70 mRNA levels increased markedly as described, whereas hsc70 mRNA increased only slightly (Fig. 1B, lanes 1-4). By treatment with either

Fig. 1. Changes in the amount of hsc70 or hsp 70 mRNA during differentiation.

A) The upper part shows a restriction map of hsc $70 \mathrm{cDNA}$; the lower part, of hsp 70 genomic DNA (about $5 \mathrm{kbp}$ ). Thick lines, open reading frames (ORF); thin lines, nontranslated sequence; shaded lines, fragments used as hybridization probes; B, BamHI; E, EcoRI; H, HindIII. B) Total RNA ( $8 \mu \mathrm{g})$ prepared from normal growing U937 cells (N; lanes $1,3,5)$ or cells treated with $150 \mu \mathrm{M} \mathrm{ZnSO}_{4}$ for $4 \mathrm{~h}(\mathrm{Zn}$; lanes $2,4,6$ ) was hybridized with 0.56 (lanes 1,2) or $\mathrm{pH} 2.3$ (lanes 3 , 4). C) Total RNA ( $8 \mu \mathrm{g}$ ) prepared from growing U937 cells (N; lanes $1,4)$, cells treated with $0.1 \mu \mathrm{g} / \mathrm{ml}$ TPA for 2 days (T; lanes 2,5 ) or treated with $1 \mu \mathrm{M}$ RA for 3 days $(\mathrm{R}$; lanes 3,6 ) was hybridized with c0.56 (lanes 1, 2, 3). Lanes 5 and 6 in (B) and lanes 4, 5 and 6 in (C) show RNA stained with ethidium bromide before Northern transfer. D) RNA was prepared from an equal number of cells at the indicated time after TPA treatment and hybridized with 0.56 . The autoradiograph (inset) was analyzed by BA100.

A)

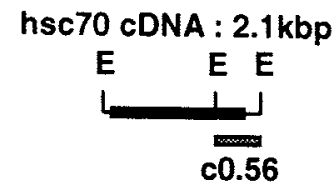

hsp70 genomic DNA : 5kbp<

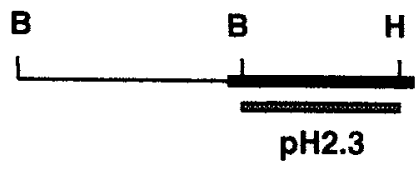

B)

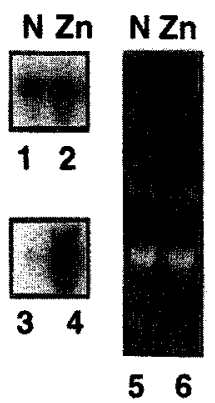

C)
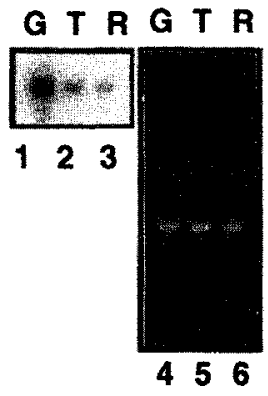

D)

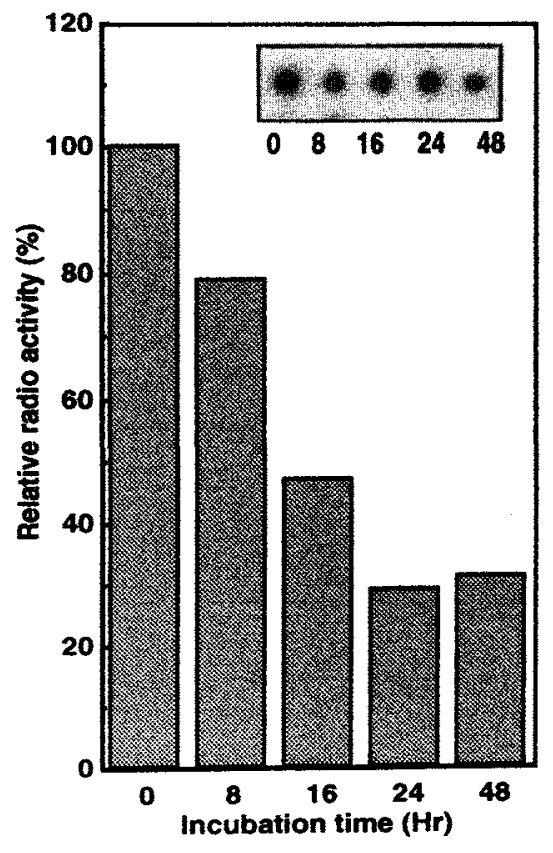

Fig. 1. 

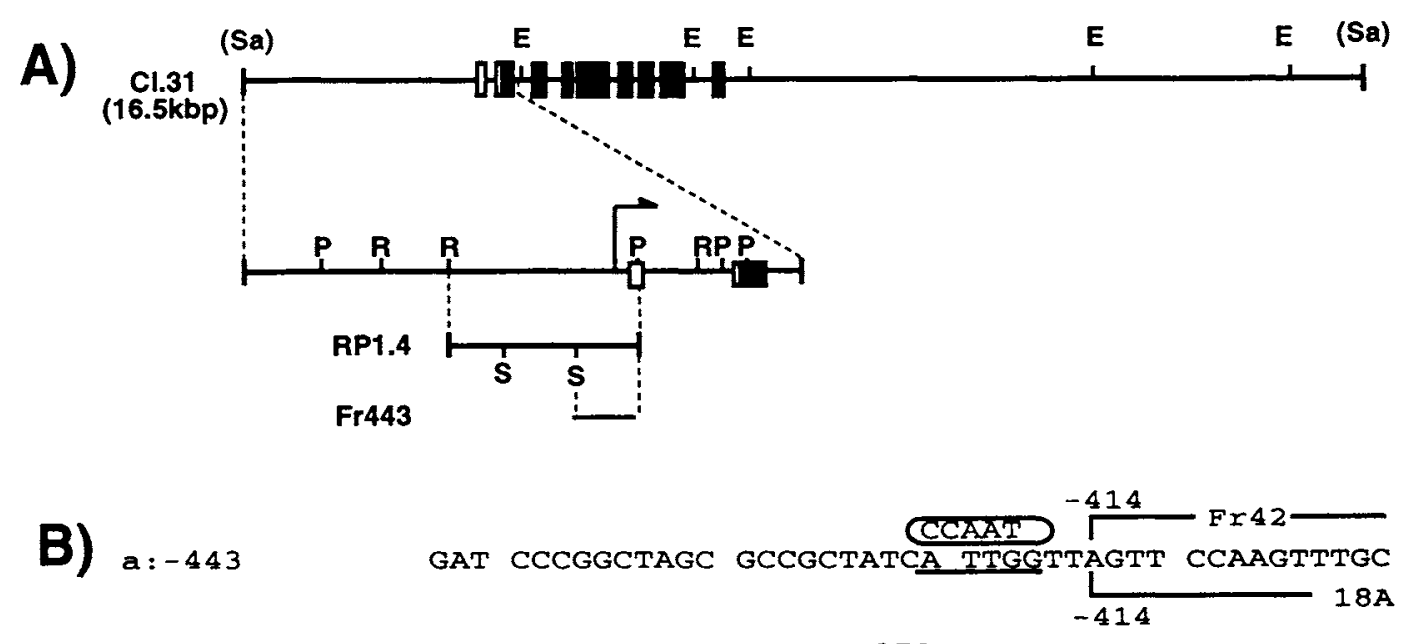

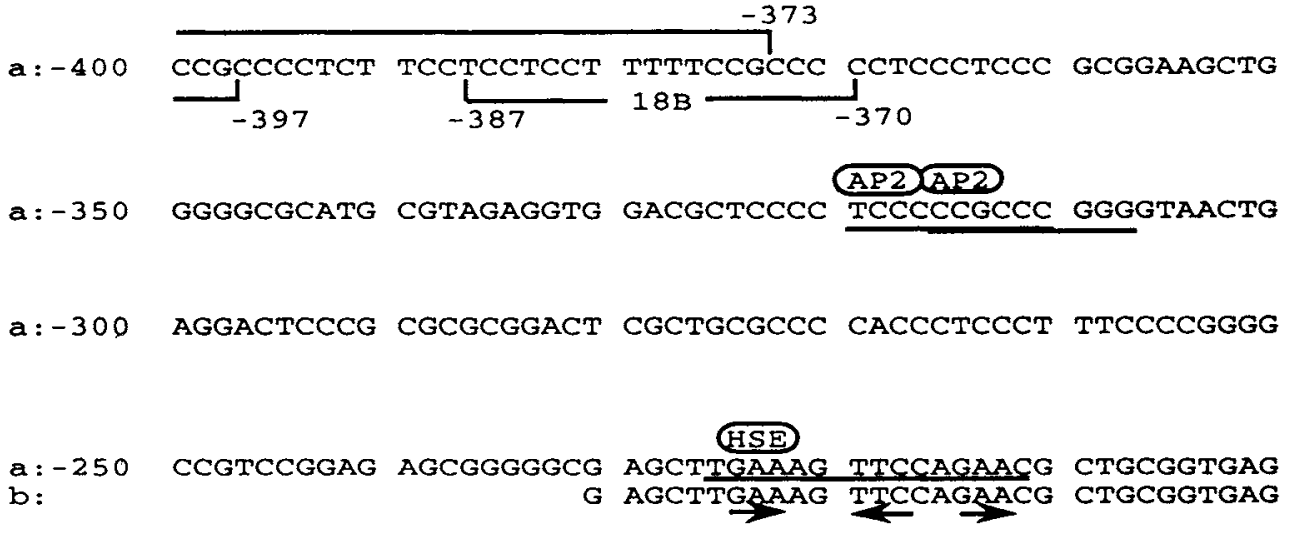

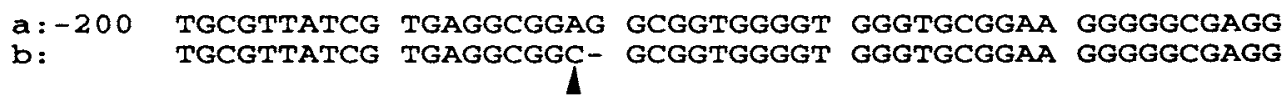
a:-150 CCCGAGGAGT GGAGCCGGGC TTGTGATTGG GTCTTGTAAG GGCAGCCGGG b: --CGAGG-GT GGAGCCG--- TTGTGATTGG GTCTTGTAAG GGCAGCC-GG CGTTGTGA

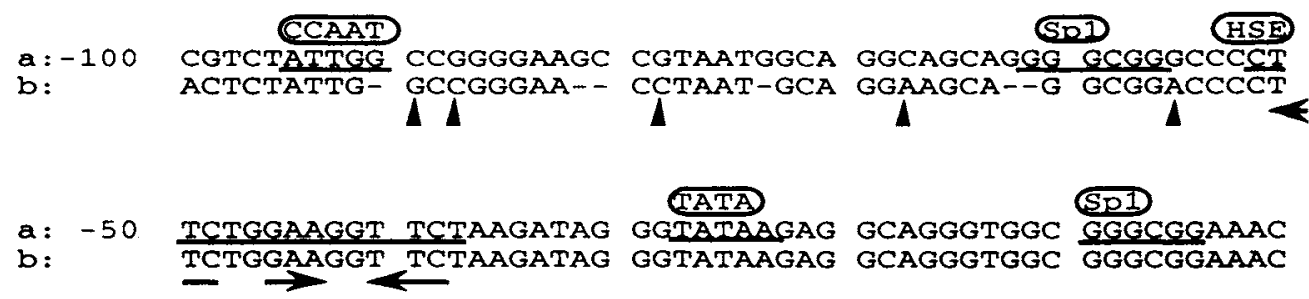

Fig. 2. DNA sequence of the $5^{\prime}$ upstream region of the hsc70 gene. The $5^{\prime}$ upstream region was obtained from $\mathrm{Cl} .31$ (A) and the nucleotide sequence of Fr443 is shown together with the sequence reported by Dworniczak and Mirault (9) (B).

A) open boxes, nontranslated exon; filled boxes, ORF; arrow on the second line, transcription initiation point; E, EcoRI; P, PstI; R, RsaI; S, Sau3AI. B) a: Sequence of the nontranslated region of Fr443. b: Sequence reported by Dworniczak and Mirault (9). Differences from Fr443 are indicated by brackets (inserted nucleotide), minus sign (deleted nucleotide), or arrow heads (exchanged nucleotide). Fr42, 18A and 18B indicated were used as probes in gel-shift analysis. CCAAT, CAT box; AP2, AP2 binding site; HSE, heat shock element; Sp1, Sp1 binding site. Horizontal arrows indicate units of heat shock element. 
TPA or RA, the amount of hsc70 mRNA decreased to less than $20 \%$ that of proliferating cells when compared on the basis of the same amount of RNA (Fig. 1C). The time course of the amount of hsc70 mRNA produced during differentiation into macrophages was examined. It decreased to $30 \%$ of that of the proliferating cells after $24 \mathrm{~h}$ (Fig. 1D) when compared on the basis of the same cell number. In the following experiments, we compared the amounts of hsc 70 mRNA and HSC 70 protein using the same number of cells before and after differentiation because upon differentiation, the cellular content of either the mRNA or protein varied drastically.

To examine the regulatory regions of the hsc70 gene, an approximately $1.4 \mathrm{kbp}$ upstream DNA fragment was cloned into a CAT reporter plasmid (Fig. 2A, MATERIALS \& METHODS). The relative activity of the CAT constructs was assayed following transfection into proliferating U937 cells (Fig. 3). The level of CAT activity was the same using a $1.4 \mathrm{~kb} 5^{\prime}$ flanking fragment and a $443 \mathrm{bp}$ fragment, suggesting that this fragment covered the upstream regulatory region. Examination of the nucleotide sequence of the $443 \mathrm{bp}$ fragment indicated the presence of two HSEs located at -226 to -212 and -52 to -38 , both of which were comprised of only three units of ${ }^{5} \mathrm{NGAAN}^{3}$ (Fig. 2B). In addition to these HSEs, the presence of CCAAT boxes, Sp1 binding sites

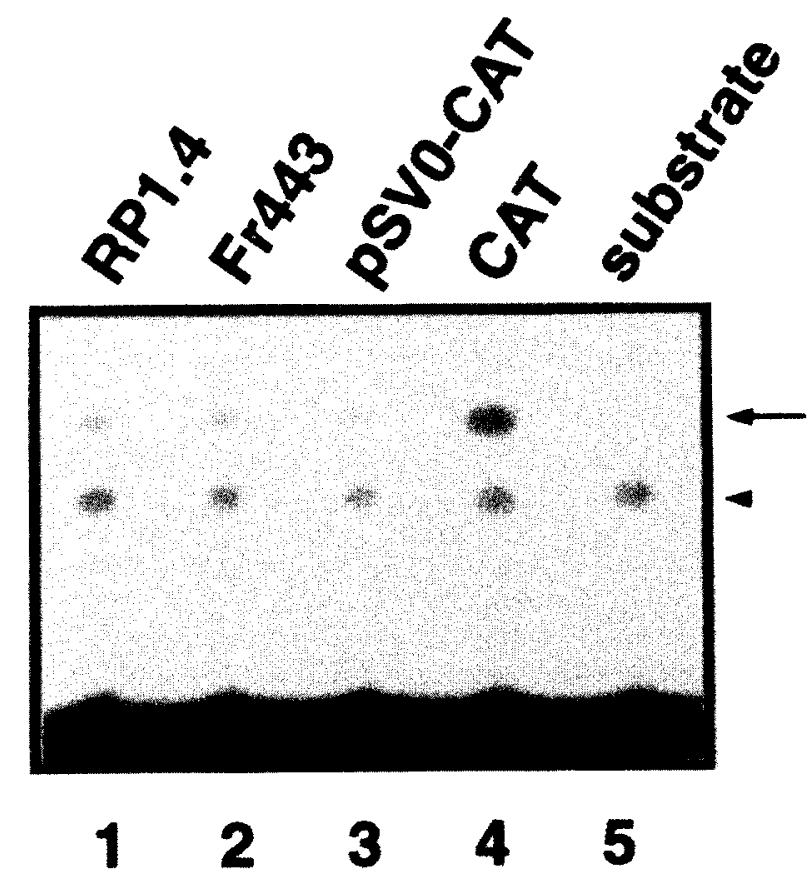

Fig. 3. Enhancer activity of the hsc70 $5^{\prime}$ upstream region. Reporter plasmids $(2 \mu \mathrm{g})$ containing fragment RP1.4 or Fr 443 were transfected into $2 \times 10^{6}$ U937 cells. After $48 \mathrm{~h}, \mathrm{CAT}$ activity of the cell lysate was analyzed. Arrow, acetylated chloramphenicol; arrowhead, contaminated material in the substrate. and AP2 binding sites was also confirmed. To examine the role of these elements in the expression of hsc70, we introduced a subfragment of this upstream regulatory region into the CAT vector. Typical results of the CAT assay are shown in Figs. 4A and 4B. Similar results were reproducibly obtained in several experiments. From these results, we identified subfragments with potential regulatory function; a $130 \mathrm{bp} 5^{\prime}$ terminal fragment (Fr130) and a 150 bp $3^{\prime}$ terminal fragment (Fr150) con-

\section{A)}

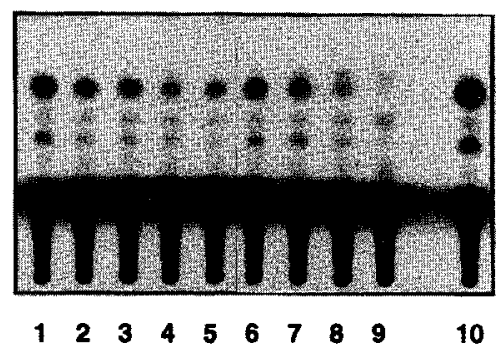

B)

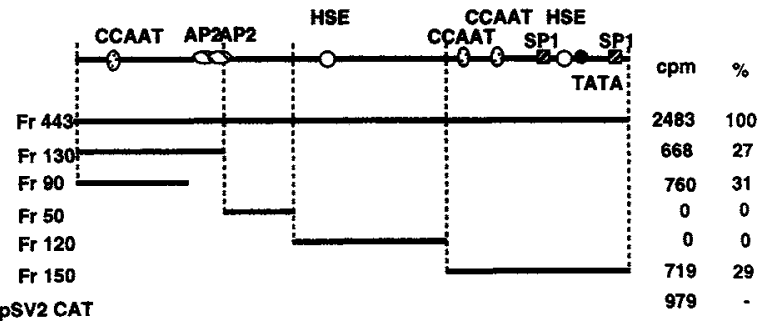

c)

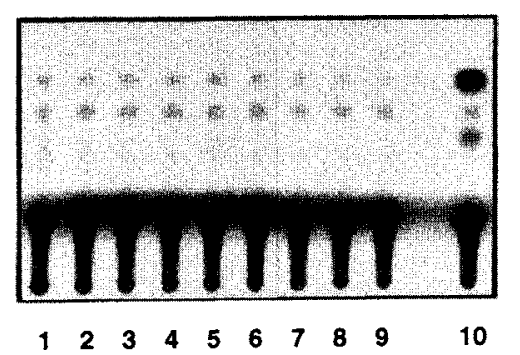

Fig. 4. Enhancer activity of Fr443 subfragments in growing or differentiated U937 cells.

A) Subfragments of Fr443 created by restriction enzyme digestion were inserted into pCAT-A (Fr130, 90, 50, 120) or pSK-CAT (Fr150) and their CAT activities were analyzed as in Fig. 3A. Lane 1, Fr443; lane 2, Fr130; lane 3, Fr90; lane 4, Fr50; lane 5, Fr120; lane 6, Fr150; lane 7, pSV2-CAT; lane 8, pCAT-A; lane 9, mock transfection; lane 10, CAT enzyme of $E$. coli $5 \mathrm{pg}$. B) Results from Fig. 3A are illustrated together with a map of Fr443. C) Eight $h$ after transfection, cells were treated with $0.01 \mu \mathrm{g} / \mathrm{m} 1$ TPA for $40 \mathrm{~h}$, then CAT activity was measured. Plasmids used in each lane were the same as in (A). 


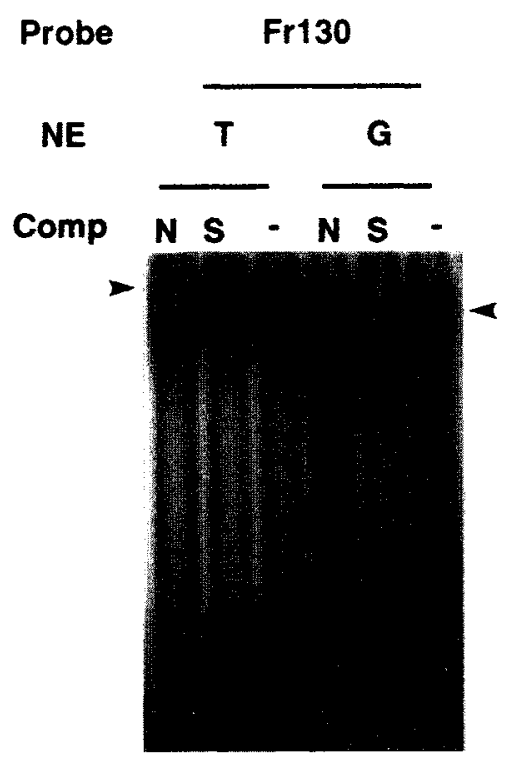

$\begin{array}{llllll}1 & 2 & 3 & 4 & 5 & 6\end{array}$
Fr50

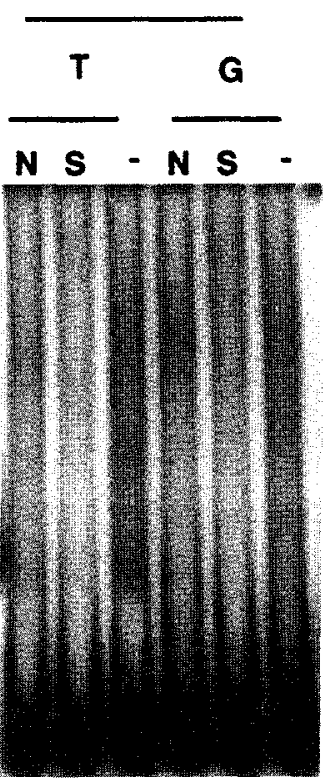

$\begin{array}{llllll}7 & 8 & 9 & 10 & 11 & 12\end{array}$
Fr120

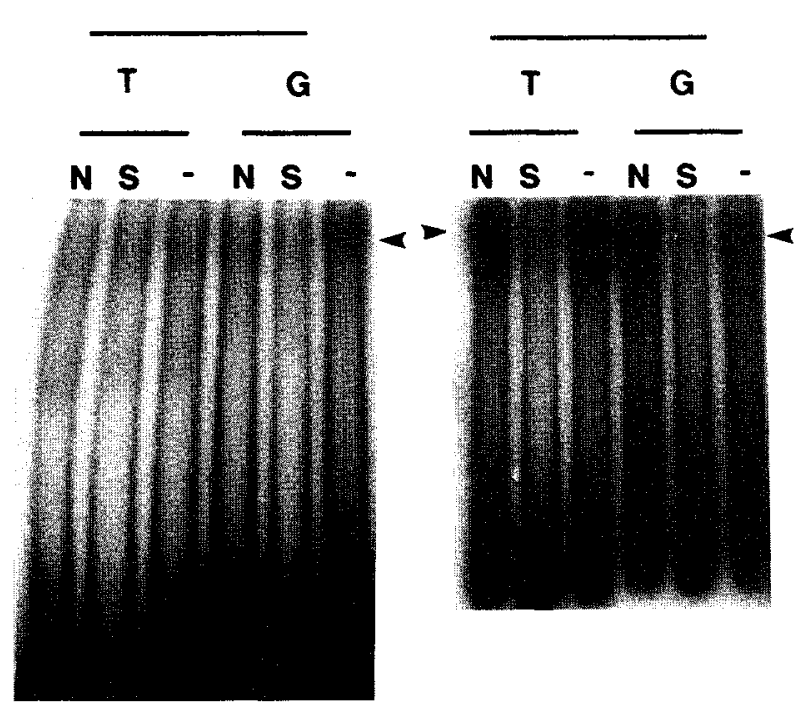

$\begin{array}{llllll}13 & 14 & 15 & 16 & 17 & 18\end{array}$
Fr150

Fig. 5. Gel-shift analysis of Fr443 subfragments.

Labeled fragments, Fr130 (lanes 1-6), Fr40 (lanes 7-12), Fr120 (lanes 13-18) and Fr150 (lanes 19-24) were incubated with nuclear extracts (NE) prepared from growing U937 cells (G) or TPA-induced differentiated cells (T). Reaction mixtures were analyzed on native-PAGE with a low salt buffer. Comp, DNA competitor; N, non-specific DNA competitor (sonicated salmon sperm DNA, $\times 100$ ); S, specific competitor (unlabeled probe, $\times 100$ ); - , without competitor.

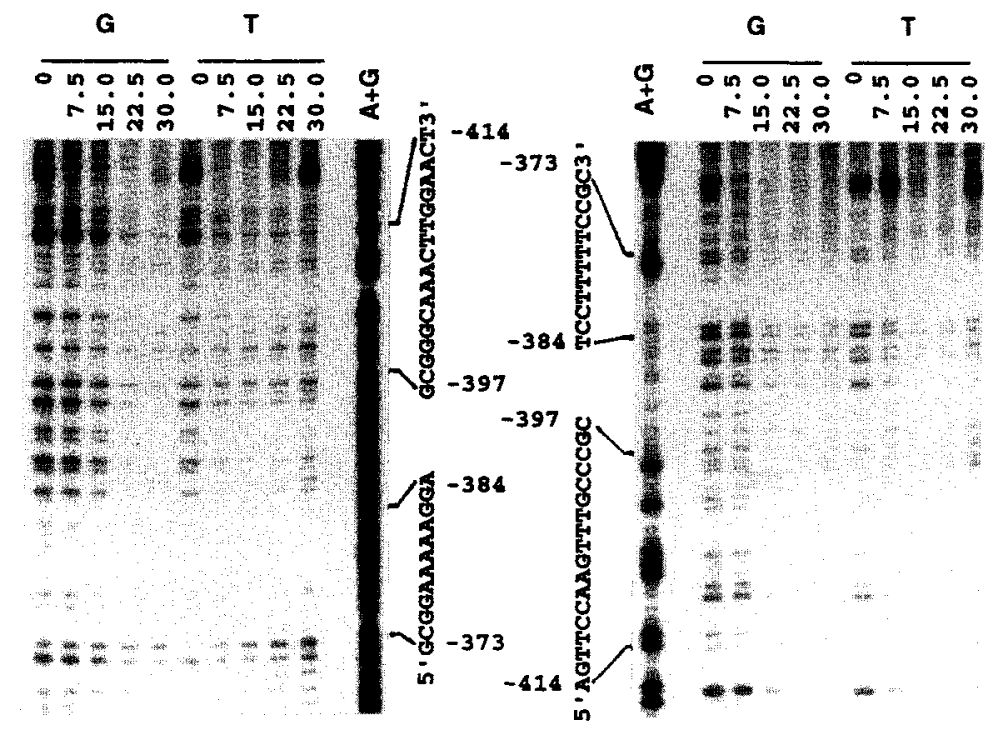

Fig. 6. Footprint analysis of Fr130.

Fr130 labeled at one terminal was incubated with various amounts of NE prepared from growing U937 cells (G) or TPA-treated cells (T) and then digested with DNaseI. Numbers under $G$ or T indicate the amount $(\mu \mathrm{g})$ of NE in the reaction mixture. [A $+\mathrm{G}$ ]: Fr 130 digested by a chemical method at nucleotides $\mathrm{A}$ or $\mathrm{G}$ as the size marker. 
taining the TATA-element. Comparison of CAT activity levels in undifferentiated versus differentiated cells revealed that these two fragments led to down-regulation of gene expression (Fig. 4C). Since transcriptional activity was higher in proliferating cells than in nonproliferating cells, the differences observed in the CAT assay reflect in vivo regulation and suggest that the Fr130 and Fr150 fragments have an important regulatory function (Figs. 4A, 4C). By comparison, the fragments Fr50 and Fr120 which contain HSEs have very little regulatory function in proliferating or differentiated cells.

In order to identify trans-acting factors which may be important in hsc70 regulation, the fragments Fr130, Fr50, Fr120 and Fr150 were subjected to a gel-shift assay, as shown in Fig. 5. As expected from the results of the CAT assay, both Fr130 and Fr150 formed complexes with nuclear extracts (NE) prepared either from proliferating (G-NE) or from differentiated cells (TNE). These complexes appear to represent specific complexes as each band was no longer detected following the addition of an excess of the unlabeled DNA fragment but no displacement occurred with unrelated DNA segments. Fr50 did not form any specifc bands while Fr 120 formed a faint but specific band with either G-NE or T-NE.

Comparison of the complexes formed from extracts of proliferating and nonproliferating cells with Fr130 revealed consistent differences in the electrophoretic mobility of the complexes. One interpretation of these results is that the nature of the protein complex formed in Fr130 differs in differentiated cells. This observation may have some relation to the suppression of hsc 70 transcription in differentiated cells.

To further establish that DNA-protein interactions vary according to the state of cell growth, DNA footprint analysis was carried out with Fr130 using G-NE or T-NE. A typical result, shown in Fig. 6, revealed that two regions, from -405 to -399 and from -382 to -376 , were protected from nuclease digestion.

We synthesized a DNA fragment of $42 \mathrm{bp}$ (from -144 to -373 , Fr42) covering these two protected regions and performed a gel-shift assay using these oligonucleotides. Results are shown in Fig. 7A. With G-NE, two specific bands were obtained and with T-NE, two additional bands were formed. All bands were diminished with the addition of the specific competitor. Fur-
A)

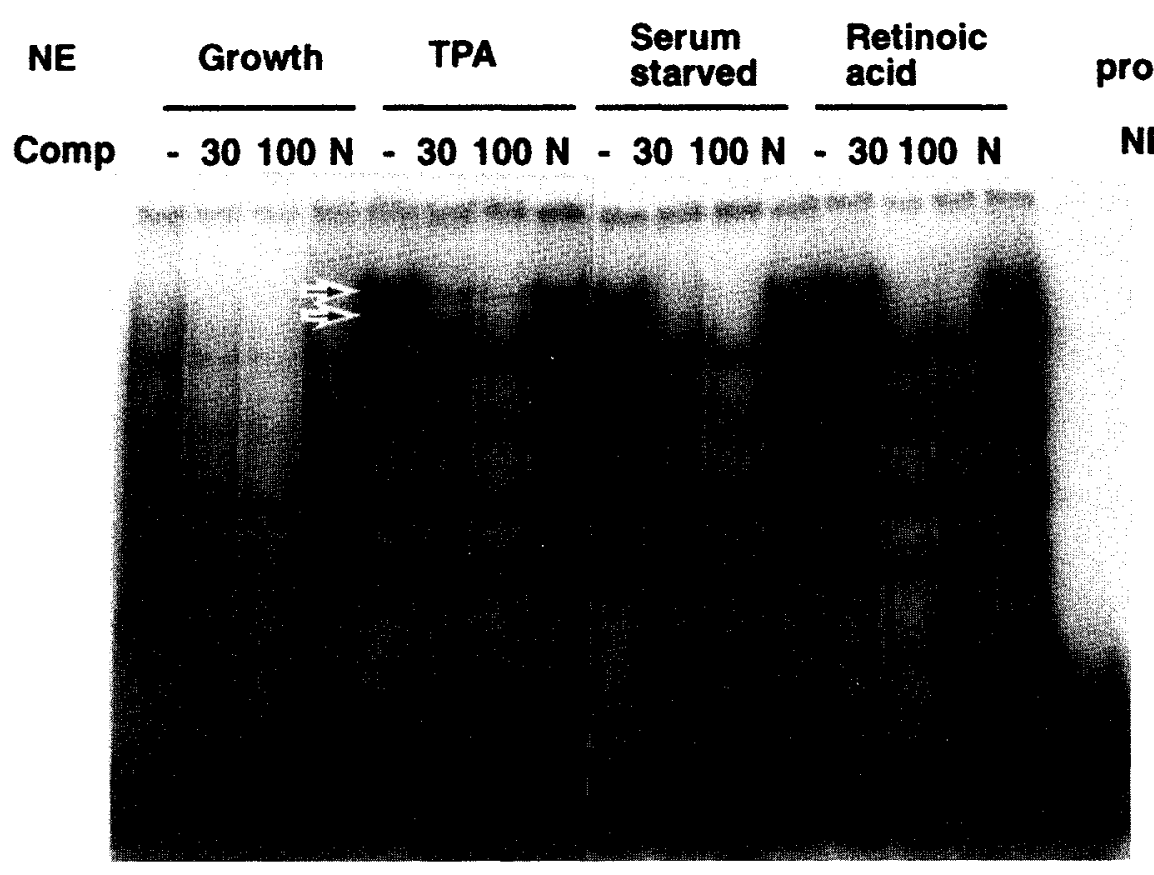

B)

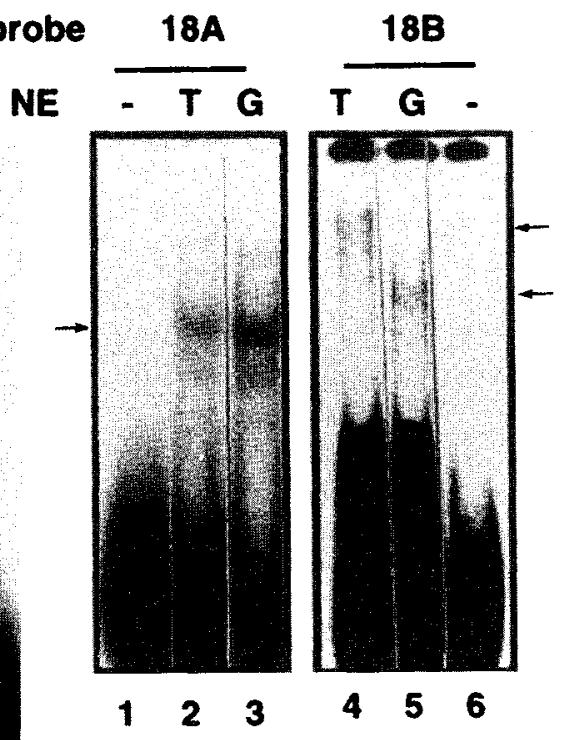

\section{$\begin{array}{lllllllllllllllll}1 & 2 & 3 & 4 & 5 & 6 & 7 & 8 & 9 & 10 & 11 & 12 & 13 & 14 & 15 & 16 & 17\end{array}$}

Fig. 7. Gel-shift analysis with smaller DNA fragments.

A) Labeled Fr42 was incubated with NE prepared from growing U937 cells (lanes 1-4), TPA-treated cells (lanes 5-8), serum-starved cells (lanes 9-12), RA-treated cells (lanes 13-16), or no cells (lane 17). Unlabeled Fr42 (30 and 100 indicate $\times 30$ and $\times 100$ respectively) or sonicated salmon sperm DNA $(\mathrm{N} ; \times 100)$ was added as competitor. B) Labeled $18 \mathrm{~A}$ or $18 \mathrm{~B}$ was incubated with NE prepared from growing U937 cells $(\mathrm{G})$ or TPAtreated cells $(\mathrm{T})$. 
thermore, NE prepared from cells which had been either deprived of serum or treated with retinoic acid formed the same bands as those of T-NE. Under the latter two conditions, hsc70 mRNA decreased, as described above.

To determine the relationship between the regions protected from nuclease digestion and the sequences forming complexes with nuclear extracts, two oligonucleotides, 18A (from -414 to -397 ) and 18B (from -387 to -390 ), were synthesized and examined for complex formation using a gel-shift assay. The results (Fig. 7B) indicate that 18A formed the same-sized DNA-protein complexes using extracts from either G$\mathrm{NE}$ or T-NE, and $18 \mathrm{~B}$ formed a complex with G-NE with a size almost the same as that of the complexes formed with 18A. However, T-NE formed a larger complex with $18 \mathrm{~B}$. These results suggest that the region corresponding to $18 \mathrm{~B}$ may interact with additional protein in extacts from differentiated cells.

We also determined the amount of HSC70 protein produced during the course of differentiation using two different antibodies (MATERIALS \& METHODS). Surprisingly, the amount of HSC70 increased after differentiation not only in macrophages but also in monocytes (Fig. 8). The two different antibodies gave similar results and the ratios of the amounts of HSC70 in macrophages and monocytes to that in proliferating cells were $2.0 \sim 3.5$ and $1.1 \sim 1.3$, respectively. In this context, the ratios of the amount of total protein in TPA-treated and RA-treated cells to that in proliferating cells were $1.26 \sim 1.33$ and $0.58 \sim 0.61$, respectively. Changes in the amount of HSC70 were determined for 5 days after TPA treatment. The level increased for three days and

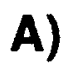

\section{G}

$\mathbf{R}$

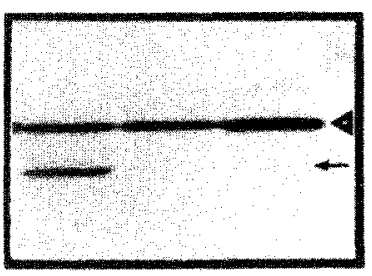

Fig. 8. Estimation of HSC70 and HSP70 proteins in growing or differentiated cells.

Cell lysate prepared from growing cells $(\mathrm{G})$, RA-induced monocytes (R) or TPA-induced macrophages (T) was transferred to PVDF membrane filter after SDS-PAGE, reacted with monoclonal antibody 1B5 (A) or polyclonal antibody No. 4 (B) and stained with Immuno Stain HRP (Konica, Tokyo, Japan). Cell lysate prepared from $1 \times 10^{5}$ cells and that from $2 \times 10^{5}$ cells were used for (A) and (B), respectively. Open triangle, HSC70 protein; filled triangle, HSP70 protein; arrow, putative degraded HSC70. remained at the higher level thereafter (Fig. 9). The polyclonal antibody used in this experiment detected HSP70 as well as HSC70 (15). Proliferating U937 cells produced barely detectable amounts of HSP70 but the amount increased after treatment with either TPA or RA, similarly to the case of HSC70 (Figs. 8 and 9). These results were apparently inconsistent with those

A)
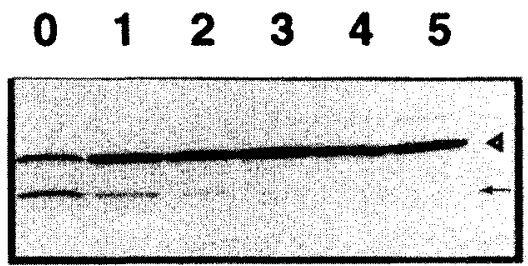

B)

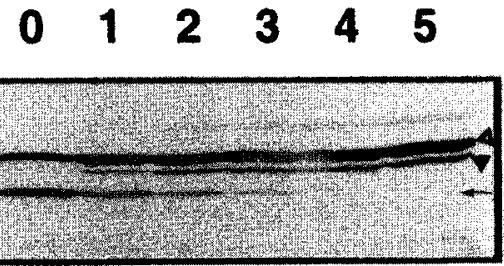

C)

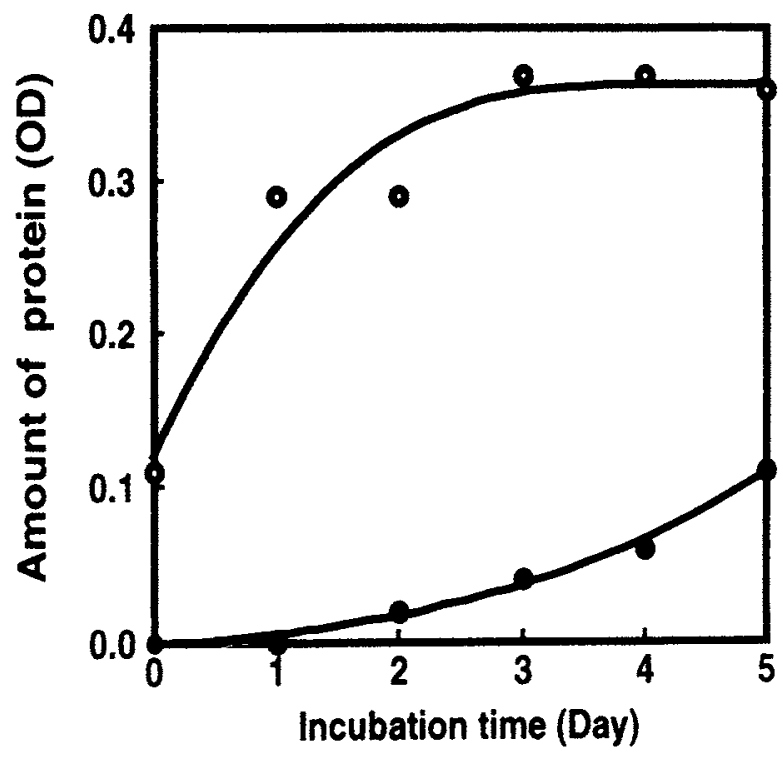

Fig. 9. Changes in HSC70 protein in differentiating U937 cells. A) Western blot with 1 B5 using a cell lysate of $1 \times 10^{5}$ cells treated with $0.1 \mu \mathrm{g} / \mathrm{ml}$ TPA. B) Western blot with No. 4 using a cell lysate of $2 \times 10^{5}$ cells treated with TPA. C) Results in (B) were analyzed by digitizer. Open triangle (A, B) and open circle (C), HSC70 protein; filled triangle (B) and filled circle (C), HSP70 protein; arrow (A, B), putative degraded HSC70 protein. 


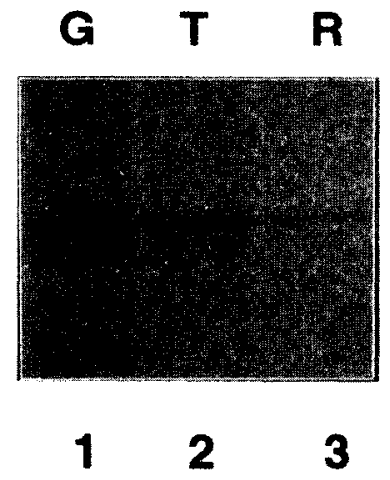

Fig. 10. Rate of HSC70 protein synthesis. Cells labeled with $\left.{ }^{35} \mathrm{~S}\right]$ methionine for $2 \mathrm{~h}$ after treatment with TPA for 2 days (T), RA for 2 days (R), or without treatment $(G)$. A cell lysate of $10^{6}$ cells was subjected to SDS-PAGE after immunoprecipitation using antibody 1B5.

demonstrating a decrease in the amount of mRNA (Fig. 1). Consequently, the rate of synthesis of HSC70 was also determined by pulse labeling with $\left[{ }^{35} \mathrm{~S}\right]-\mathrm{Met}$ and immunoprecipitation. As shown in Fig. 10, the rate of HSC70 synthesis was suppressed by differentiation in accordance with the suppression of mRNA synthesis of this gene.

When we attempted to resolve this discrepancy by treating the cells with differentiation inducer, the transcription and translation of hsc70 were suppressed whereas the amount of HSC70 protein increased compared with that of proliferating cells. These results suggest that the turnover of HSC70 in proliferating cells is rapid compared to that of differentiated cells.

\section{DISCUSSION}

Taking into consideration that HSC70 performs various functions in normal cells such as those of molecular chaperone (30), and that the hsc70 gene contains three U14 genes in its introns (24), transcription of hsc70 must be regulated by factors other than by a response to physiological stress.

With TPA treatment, both hsc70 mRNA and the rate of HSC 70 synthesis decreased to about $30 \%$ of that of proliferating cells. The decrease in the amount of hsc70 mRNA during differentiation was consistent with that obtained with mouse F9 cells (11), although the decrease was only slight in F9. This difference might be due to the fact that U937 differentiated terminally and was arrested in the Go state whereas F9 continued to proliferate after differentiation and consequently transcribed more hsc70 $(37,14)$.

In the CAT assay, the upstream regulatory region was confined to about $450 \mathrm{bp}$. The nucleotide sequence of this region was determined and was shown to contain several known nuclear factor binding sites including two HSEs. Each HSE was found to be composed of only three 5'NGAAN3' units and this would explain why hsc70 did not respond to stress as strongly as did hsp70 (35). The sequence controlling transcription in relation to differentiation is Iocalized from -414 to -370 (Fr42) from the results obtained in this study. In this assay, the promoter regions of the proliferating cells were assigned to two stretches in the $5^{\prime}$ terminal and $3^{\prime}$ terminal regulatory regions, as shown in Fig. 4B.

Both of these activities were suppressed in differentiated cells (Fig. 4C), suggesting that these regions are concerned with suppression. While the $3^{\prime}$ terminal region formed similarly sized complexes with either G-NE or T-NE (Fig. 5), the 5 terminal region, Fr42, formed larger complexes with $\mathrm{T}-\mathrm{NE}$ than with G-NE, prompting us to further analyze Fr42. To study the mechanism of formation of the larger complexes, we determined the sequence that bound these complexes using synthetic oligonucleotides and confirmed that the same nucleotide sequence (18B) formed complexes either with G-NE or with T-NE.

In order to explain the mechanism responsible for changes in the migration distance, the increase in the mass of complexes formed on the same sequence should be considered. It is possible that during differentiation, new factors are produced which can exchange with the complexes formed in proliferating cells. It is also possible that some factors are replaced with others or that a portion of the factors is modified. These possibilities are now under investigation.

The decrease in the rate of HSC70 protein synthesis during differentiation is consistent with the decrease in hsc70 mRNA. The increase in the cellular content of HSC70, however, was at variance with the decrease in mRNA. Since the synthesized protein could accumulate in terminally differentiated cells, it is possible that the HSC70 content would exceed that of the proliferating cells, even if its rate of synthesis was slower than that in proliferating cells. It is also possible that HSC70 degrades more rapidly in proliferating cells than in differentiated cells since this protein is stable in macrophages. The latter would also be possible in this case since at least two bands (one of them indicated by an arrow in Figs. 8 and 9) other than HSC70 were detected by Western blotting using two completely different antibodies for HSC70. Furthermore, the amount of these smaller proteins decreased during the course of differentiation in opposition to the increase in HSC70. It is possible that these two smaller bands detected with anti-HSC70 antibodies were specific degradation products of HSC70 that retained epitopes recognized by the antibodies. Therefore, it is conceivable that together with the rate of synthesis, the turnover of HSC70 has the largest effect on the cellular content of this protein. These 
metabolic differences would explain the marked increase in the amount of HSC70 in differentiated macrophages. The degradation of HSC70 is of interest in several respects, particularly in how it is related to the regulation of the synthesis of HSC70 because there have been many experimental findings supporting the idea that HSC70 synthesis may be regulated by the amount of HSC70 itself (1).

Acknowledgments. We thank R.I. Morimoto for critical reading of the manuscript and for encouragement. This work was supported in part by Grants-in-Aid for scientific research from the Japanese Ministry of Education, Science and Culture, the Science Research Promotion Fund of the Japan Private School Promotion Foundation, and by Fujita Health University.

\section{REFERENCES}

1. Abravaya, K., Myers, M.P., Murphy, S.P., and Morimoto, R.I. 1992. The human heat shock protein hsp70 interacts with HSF, the transcription factor that regulates heat shock gene expression. Genes \& Dev., 6: 1153-1164.

2. Agoff, S.N., Hou, J., LinZer, D.I.H., and WU, B. 1993 . Regulation of the human hsp70 promoter by p53. Science, 259: 8487.

3. Beckman, R.B., Mizzen, L.A., and Welch, W.J. 1990 . Interaction of hsp70 with newly synthesized proteins: Implications for protein folding and assembly. Science, 248: 850-854.

4. Chirico, W.J., Waters, M.G., and Blobel, G. $1988.70 \mathrm{k}$ heat shock related proteins stimulate protein translocation into microsomes. Nature, 332: 805-810.

5. Chomczynski, P. and SACCHI, N. 1987. Single-step method of RNA isolation by acid guanidinium thiocyanate-phenol-chloroform extraction. Anal. Biochem., 162: 156-159.

6. Curci, A., Berilacqua, A., Fiorenza, M.T., and Mangia, F. 1991. Developmental regulation of heat-shock response in mouse oogenesis: Identification of differentially responsive oocyte classes during graafian follicle development. Developmental Biol., 144: 362-368.

7. Deshaies, R.J., Koch, B.D., Werner-Washburne, M., Craig, E.A., and ShECKMAN, R. 1988. A subfamily of stress proteins facilitates translocation of secretory and mitochondrial precursor polypeptides. Nature, (London) 332: 800-805.

8. Dignam, J.D., Lebovitz, R.M., and Roeder, R.G. 1983 . ACcurate transcription initiation by RNA polymerase II in a soluble extract from isolated mammalian nuclei. Nucleic Acid Res., 11: $1475-1489$.

9. DWorniczak, B. and Mirault, M.-E. 1987. Structure and expression of a human gene coding for a $71 \mathrm{kd}$ heat shock ' $c 0$ nate' protein. Nucleic Acid Res., 15: 5181-5197.

10. Flynn, G.C., Chappeli, T.G., and Rothman, J.E. 1989. Peptide binding and release by proteins implicated as catalysts of protein assembly. Science, 245: 385-390.

11. Giebel, L.B., DworniczaK, B.P., and Bautz, E.K.F. 1988. Developmental regulation of a constitutively expressed mouse mRNA encoding a 72 -kDa heat shock-like protein. Developmental Biol., 125: 200-207.

12. Gorman, C.M., Moffat, L.F., and Howard, B.H. 1982 . Recombinant genomes which express chloramphenicol acetyltransferase in mammalian cells. Mol. Cell. Biol., 2: 1044-1051.

13. Gromou, P.S. and Celis, J.E. 1991. Identification of two mo- lecular chaperons (HSX70, HSC70) in mature human erythrocytes. Exp. Cell Res., 195: 556-559.

14. Hansen, L.K., Houchins, J.P., and O'Leary, J.J. 1991. Differential Regulation of HSC70, HSP70, HSP90a and HSP90b mRNA expression by mitogen activation and heat shock in human lymphocytes. Exp. Cell Res., 192: 587-596.

15. Hattori, H., Kameda, T., LoKeshwar, B., Laszlo, A., and OHTSUKA, K. 1993. A stress-inducible $40 \mathrm{kD}$ protein (hsp40): purification by modified two-dimensional gel electrophoresis and co-localization with hsc70 (p73) in heat-shocked Hela cells. J. Cell Science, 104: 629-638.

16. HirochiKA, H., BroKer, T.R., and Chow, L.T. 1987. Enhancers and trans-acting E2 transcriptional factors of papillomaviruses. J. Virol., 61: 2599-2606.

17. Hosoya, H. and Marunouchi, T. 1992. Differentiation and dedifferentiation of the human monocytic leukemia cell line, U937. Cell Str. Func., 17: 263-269.

18. Hunt, C.K. and MoRimoto, R.I. 1985. Conserved features of eukaryotic $h s p 70$ gens revealed by comparison with the nucleotide sequence of human hsp70. Proc. Natl. Acad. Sci. USA, 82: $6455-6459$.

19. KAto, H.T. and Nevis, J.R. 1983. Transcriptional activation and subsequent control of the human heat shock gene during adenovirus infection. Mol. Cell. Biol., 3: 2058-2065.

20. Kingston, R.E., Baldwin, Jr., A.S., and Sharp, P.A. 1984. Regulation of heat shock protein 70 gene expression by c-myc. Nature (London), 312: 280-282.

21. LAEMMLI, U.K. 1970. Cleavage of structural proteins during the assembly of the heat of bacteriophage T4. Nature (London), 227: $680-685$.

22. Larson, J.S., Schuetz, T.J., and Kingston, R.E. 1988. Activation in vitro of sequence-specific DNA binding by a human regulatory factor. Nature (London), 335: 372-375.

23. Leverette, R.D., ANdres, M.T., and Maxell, E.S. 1992. Mouse U14 snRNA is a processed intron of the cognate hsc70 heat shock pre-messenger RNA. Cell, 71: 1215-1221.

24. LiU, J. and Maxell, E.S. 1990. Mouse U14 snRNA is encoded in an intron of the mouse cognate hsc70 heat shock gene. $\mathrm{Nu}$ cleic Acid Res., 18: 6565-6571.

25. Milarski, K.L. and Morimoto, R.I. 1986. Expression of human HSP70 during the synthetic phase of the cell cycle. Proc. Natl. Acad. Sci. USA, 83: 9517-9521.

26. Morimoto, R.I. and MiLARSKI, K.L. 1990. Expression and function of vertebrate hsp70 genes, p. 323-359. In Stress protein in biology and medicine, (R.I. Morimoto, A. Tissieres, and C. Geogropoulos, eds.). Cold Spring Harbor Laboratory Press, Cold Spring Harbor, New York.

27. Olson, I.L. and BREITMAN, T.R. 1982. Induction of the differentiation of the human histiocytic lymphoma cell line U-937 by retinoic acid and cyclic adenocine $3^{\prime}$ : $5^{\prime}$-monophosphate-inducing agents. Cancer Res., 42: 3924-3927.

28. O'Malley, K., Mauron, A., Barchas, J.D., and Kedes, L. 1985. Constitutively expressed rat mRNA encoding a 70-kilodalton heat-shock-like protein. Mol. Cell. Biol., 5: 3476-3483.

29. Pelmam, H.R.B. 1986. Speculation on the functions of the major heat shock and glucose-regulated proteins. Cell, 46: 959 961.

30. Pelham, H.R.B. 1989. Heat shock and the sorting of luminal ER proteins. EMBO J., 8: 3171 .

31. Perkins, L.A., Doctor, J.S., Zhang, K., Stinson, L., Perrimon, N., and Craig, E.A. 1990. Molecular and developmental characterization of the heat shock cognate 4 gene of Drosophila melanogaster. Mol. Cell. Biol., 10: 3232-3238. 
32. Pinhasi-Kimhi, O., Michalovitz, D., Ben-Zeev, A., and Oren, M. 1986. Specific interaction between the p53 cellular tumour antigen and major heat shock proteins. Nature (London), 320: $182-195$.

33. SambrooK, J., Fritsch, E.F., and Maniatis, T. 1989. Molecular cloning, a laboratory manual. Cold Spring Harbor Laboratory Press, Cold Spring Harbor, New York.

34. SнI, Y. and Thomas, J.O. 1992. The transport of proteins into the nucleus requires the 70-kilodalton heat shock protein or its cytosolic cognate. Mol. CEll. Biol., 12: 2186-2192.

35. SORGER, P.K. 1991. Heat shock factor and the heat shock response. Cell, 65: 363-366.

36. Sorger, P.K., Lewis, M.J., and Pelham, H.R.B. 1987. Heat shock factor is regulated differently in yeast and Hela cells. $N a$ ture (London), 329: 81-84.
37. Sorger, P.K. and Pelham, H.R.B. 1987. Cloning and expression of a gene encoding hsc73, the major hsp70-like protein in unstressed rat cells. $E M B O J ., 6: 993-998$.

38. UNGEWICKELL, E. 1985. The 70-kd mammalian heat shock proteins are structurally and functionally related to the uncoating protein that releases clathrin triskelia from coated vesicles. EMBO J., 4: 3385-3391.

39. WELCH, W.J. and SUHAN, J.P. 1986. Cellular and biochemical events in mammalian cells during and after recovery from physiological stress. J. Cell. Biol., 103: 2035-2052.

40. Wu, B., Hunt, C., and Morimoto, R. 1985. Structure and expression of the human gene encoding major heat shock protein HSP70. Mol. Cell Biol., 5: 330-341.

(Received for publication, November 22, 1993

and in revised form December 2, 1993) 